05.1

\title{
Спектроскопическое исследование примесных и собственных нарушений строения кристаллитов в керамике ZnTe при механической обработке
}

\author{
(C) И.П. Щербаков ${ }^{1}$, А.А. Дунаев ${ }^{2}$, С.Б. Еронько ${ }^{2}$, А.Е. Чмель ${ }^{1, \uparrow}$ \\ ${ }^{1}$ Физико-технический институт им. А.Ф. Иофрфе РАН, Санкт-Петербург, Россия \\ ${ }^{2}$ Государственный оптический институт им. С.И. Вавилова, Санкт-Петербург, Россия \\ ฯE-mail: chmel@mail.ioffe.ru
}

Поступило в Редакцию 17 февраля 2020 г.

В окончательной редакции 9 ноября 2020 г.

Принято к публикации 9 ноября 2020 г.

\begin{abstract}
Проведенное ИК-спектроскопическое исследование показало присутствие в керамическом теллуриде цинка воды и углекислого газа, адсорбированных на поверхности полостей между кристаллитами. Найдено, что гидроксильные группы появляются на поверхности изделий уже на стадии полирования, а группы, принадлежащие $\mathrm{CO}_{2}$, адсорбируются в процессе хранения при нормальных условиях. Также методом фотолюминесценции обнаружено, что механическое разрушение керамики проявляется в отклонении от стехиометрического состава кристаллитов и уменьшении ширины запрещенной зоны.
\end{abstract}

Ключевые слова: ZnTe, керамика, адсорбция примесей, ИК-спектроскопия, фотолюминесценция.

DOI: 10.21883/PJTF.2021.04.50641.18249

Полупроводниковый материал теллурид цинка (ZnTe) используется как один из компонентов гетеропереходов на основе соединений группы $\mathrm{A}_{2} \mathrm{~B}_{6}$ : $\mathrm{ZnSe}, \mathrm{ZnS}, \mathrm{CdS}$. Теллурид цинка имеет интенсивное свечение в видимой области, усиливаемое легированием, что делает его перспективным материалом для приборов, излучающих свет в видимой области.

Особенностью всех видов синтеза соединений ZnTe является присутствие различных примесей, поглощающих ИК-излучение в области, где отсутствуют структурные полосы материала. В литературе имеются спектральные свидетельства присутствия воды и углекислого газа в кристаллах [1,2], порошках [3] и тонких пленках [4], хотя идентификация полос противоречива или полностью отсутствует. Наиболее подробно спектр ZnTe в области $700-4000 \mathrm{~cm}^{-1}$ рассмотрен для бинарных компонентов твердых растворов систем ZnTe-CdTe [5] и $\mathrm{ZnTe}-\mathrm{CdSe}[6]$.

Целью настоящей работы является определение стойкости керамического ZnTe к адсорбции воды и углекислого газа в процессе хранения/эксплуатации изделий, а также влияния абразивного и ударного воздействия на кристаллическое строение поверхности материала.

В работе выполнен анализ ИК-спектров пропускания и отражения поглощающих примесей и структурных дефектов в номинальной области прозрачности для керамического ZnTe. Наличие $\mathrm{H}_{2} \mathrm{O}$ и $\mathrm{CO}_{2}$ в атмосфере приводит к образованию адсорбированных слоев на поверхности, что снижает функциональные характеристики материала. Поскольку в этой области ИК-излучение при отражении глубоко проникает в образец, спектр отражения фактически близок к спектру пропускания, но с увеличенным вкладом приповерхностной зоны.
Керамика ZnTe используется также в качестве защитных покрытий оптических элементов устройств, работающих в полевых условиях, где покрытия подвергаются пылевой, водно-капельной и градовой эрозии. Структурные изменения в этом материале при абразивном и точечном ударном воздействии оценены методом фотолюминесценции (ФЛ).

Керамика ZnTe была получена путем физического осаждения из газовой фазы (PVD - physical vapor deposition). В качестве исходного сырья применялся порошкообразный теллурид цинка марки ч. Синтез проводился в вакуумной печи при остаточном давлении на уровне $1.33 \mathrm{~Pa}$ в разборном графитовом контейнере, в котором зоны испарения и конденсации разделялись пористой перегородкой. В качестве подложки использовался стеклоуглерод.

Образцы для спектроскопических исследований изготавливались в форме дисков диаметром $4 \mathrm{~cm}$ и толщиной $1 \mathrm{~cm}$ с последующей шлифовкой-полировкой плоскостей. ИК-спектры пропускания и отражения получены на фурье-спектрометре InfraSpek FSM 1201. Спектры ФЛ записаны на волоконно-оптическом спектрометре AVANTES (AvaSpec-ULSi2048L-USB2 OEM). Спектры возбуждались УФ-светодиодом HPL-H44LV1C0, излучающим на длине волны $380 \mathrm{~nm}$.

ИК-спектры отражения приведены на рис. 1 с указанием частот полос поглощения. Отнесение полос (по данным [5-12]) представлено в таблице. Спектр 1 на рис. 1 принадлежит образцу, хранившемуся после изготовления и полировки более полутора лет при комнатных условиях. Спектр 2 записан сразу после повторной полировки выдержанного образца. Можно видеть, что в спектре 1 имеется набор слабых колеба- 
Отнесение полос отражения теллурида цинка в среднем ИК-диапазоне

\begin{tabular}{c|c|c}
\hline Частота, $\mathrm{cm}^{-1}$ & Тип колебаний & Лит. ссылка \\
\hline $1090-1100$ & $\mathrm{C}-\mathrm{O}$, валентные & {$[5]$} \\
1536 & ОН, валентные & {$[10,11]$} \\
$1610-1650$ & ОН, деформационные, молекулярная & {$[5,6]$} \\
1698 & адсорбция воды & {$[9]$} \\
$2320-2380$ & $\mathrm{C}=\mathrm{O}$, валентные & {$[5,10,11]$} \\
$2950^{*}$ & $\mathrm{C}-\mathrm{O}$, валентные, молекулярная & {$[5]$} \\
$3300-3800$ & адсорбция $\mathrm{CO}_{2}$ & {$[7,8]$} \\
3400 & С-Н, валентные, технологическая & {$[12]$}
\end{tabular}

* Только в спектре пропускания.

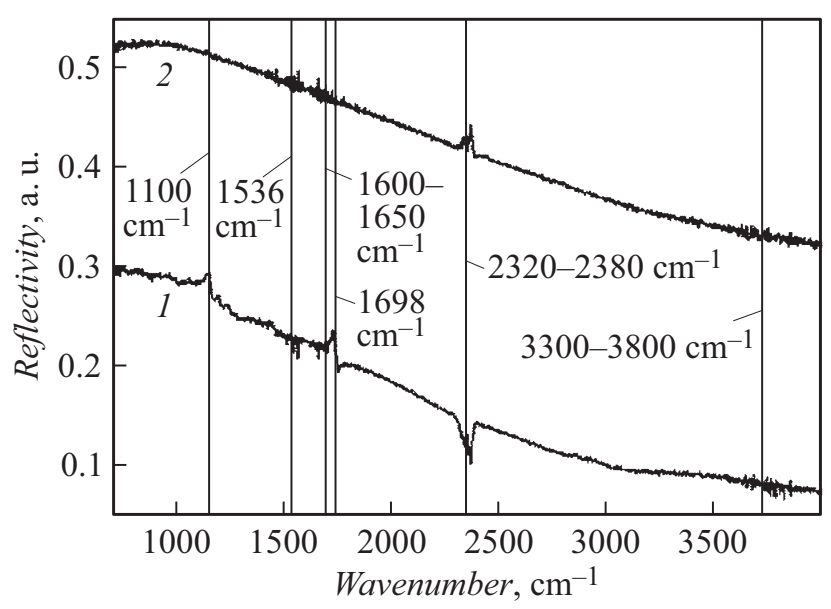

Рис. 1. ИК-спектры отражения керамики $\mathrm{ZnTe}$ после длительной выдержки на воздухе (1) и повторного полирования (2).

тельных полос воды и отчетливо выделяющихся полос углекислого газа. В повторно полированных образцах (спектр 2) интенсивность полос пленки воды осталась примерно прежней, т.е. ее адсорбция на поверхности возникает уже в процессе полировки. Слабые полосы колебаний $\mathrm{C}-\mathrm{O}\left(1100\right.$ и $\left.1698 \mathrm{~cm}^{-1}\right)$ полностью исчезли, а дублет $2320-2380 \mathrm{~cm}^{-1}$ изменил интенсивность на противоположную. Более того, в спектре пропускания (рис. 2) единственной полосой, имеющей „отрицательную“ интенсивность, характерную для спектров пропускания (с пиком полосы, направленным вниз), оказалась сложная полоса групп С-Н (дублет $\sim 2950 \mathrm{~cm}^{-1}$ ) в технологической примеси в объеме материала. Все полосы воды и углекислого газа показали фиктивный рост прозрачности (пик полосы направлен вверх) образца.

Зеркальный эффект преобразования интенсивностей объяснен локализацией адсорбированных групп $\mathrm{H}_{2} \mathrm{O}$ и $\mathrm{CO}_{2}$ не только на поверхности образца, но и на стенках пор (пространства между зернами керамики). ИК-свет многократно попадает во внутренние адсорбированные слои под различными углами из твердого материала с высоким показателем преломления $(\sim 3.5)$ в материал с низким показателем преломления $(\sim 1.3)$, т. е. возникают условия полного внутреннего отражения, при котором полосы в спектре являются полосами поглощения. Отраженный от границы с порой свет уходит в сторону входной поверхности, компенсируя поглощение на частотах примесей, т.е. повышая прозрачность образца (но не материала) на этих частотах: пористый материал прозрачнее сплошного.

Эффект абразивного и ударного воздействия пылевых частиц и осадков на оптические элементы приборов, эксплуатируемых на открытом воздухе, моделировался грубой шлифовкой поверхности образцов и ударом заостренного бойка. На рис. 3 показаны спектры ФЛ полированного и шлифованного образцов, поверхности скола и созданного механического дефекта („каверны“). Для получения спектра из полости „каверны“ (верхняя вставка на рис. 3) использован волоконный световод (нижняя вставка на рис. 3).

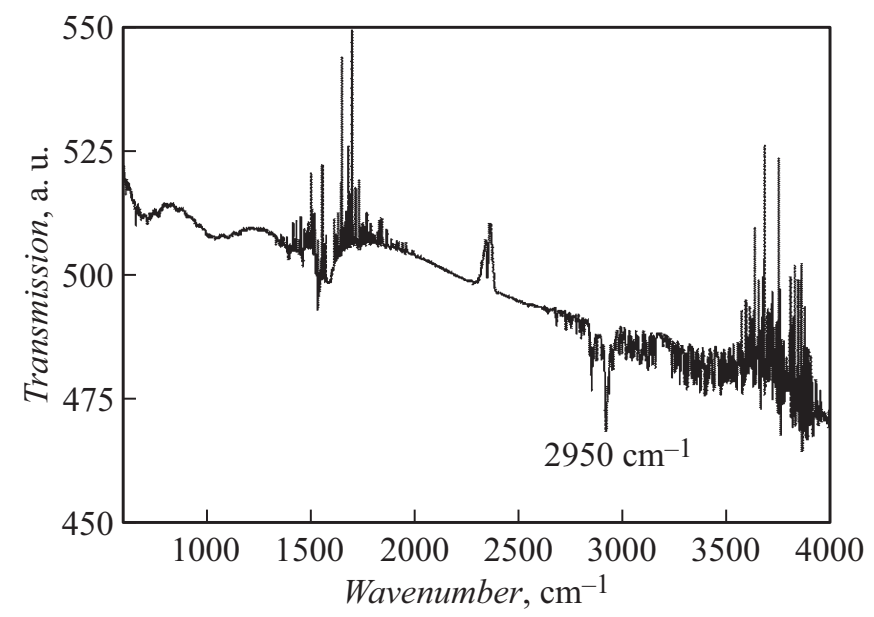

Рис. 2. ИК-спектр пропускания керамики $\mathrm{ZnTe}$ в области отсутствия структурных полос материала. 


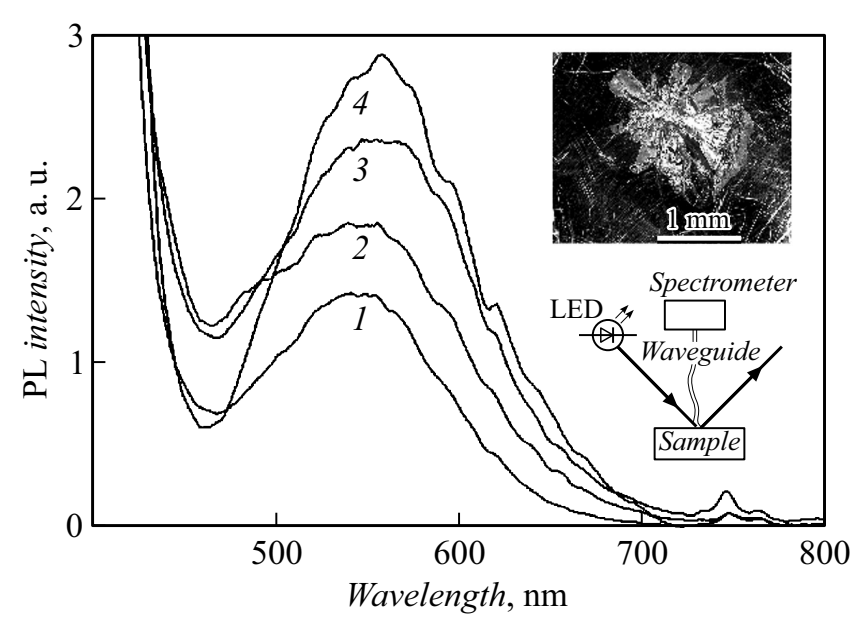

Рис. 3. Спектры люминесценции полированной поверхности (1), скола (2), „каверны“ (3), шлифованной поверхности (4). Интенсивность полос выбрана произвольно, чтобы показать последовательность смещения максимума. На верхней вставке - фотография „каверны“, на нижней - схема опыта.

В спектре ФЛ при температуре $300 \mathrm{~K}$ ширина запрещенной зоны в монокристаллах составляет $2.25 \mathrm{eV}$ [13] (расчетная диаграмма электронных уровней приведена в [14]), и соответственно полоса краевого излучения имеет частоту $\sim 550 \mathrm{~nm}$. В нашем случае пик полосы в спектре полированного образца располагался на $544 \mathrm{~nm}$, что может указывать на некоторые отклонения от стехиометрии в зернах керамики. Слабо выраженная волнистая структура на длинноволновом крыле полосы связана с возбужденными состояниями доноров и акцепторов $[15,16]$.

На рис. 3 можно видеть, что при механическом воздействии на поверхность керамики максимум полосы смещается в сторону длинных волн в последовательности: полированный образец (положение максимума $544 \mathrm{~nm})$ - скол $(547 \mathrm{~nm})$ - „каверна“ (556 nm) -шлифованный образец $(557 \mathrm{~nm})$, т. е. по мере увеличения степени повреждения кристаллитов происходит уменьшение ширины запрещенной зоны.

Проведенное спектроскопическое исследование показало, что керамический теллурид цинка содержит значительное количество адсорбированной воды и углекислого газа на поверхности полостей между кристаллитами, причем поглощение последнего в области номинальной прозрачности растет при хранении в нормальных условиях. Механическое разрушение керамики проявляется на структурном уровне в отклонении от стехиометрического состава и уменьшении ширины запрещенной зоны. Оба явления ухудшают функциональные свойства материала.

\section{Конфликт интересов}

Авторы заявляют, что у них нет конфликта интересов.

\section{Список литературы}

[1] B.B. Wang, M.K. Zhu, H. Wang, G.B. Dong, Opt. Mater., 34, 42 (2011). DOI: 10.1016/j.optmat.2011.07.017

[2] R. Yang, W. Jie, X. Sun, M. Yang, J. Semicond., 36, 093006 (2015). doi.org/10.1088/1674-4926/36/9/093006

[3] B.B. Wang, M.K. Zhu, N. Hu, L.J. Li, J. Lumin., 131, 2550 (2011). doi.org/10.1016/j.jlumin.2011.06.028

[4] J. Ohta, Y. Sugawa, K. Takao, T. Ohgai, in Proc. of the 8th Pacific Rim Int. Congress on advanced materials and processing, ed. by F. Marquis (Springer International Publ., 2016), p. 2123.

[5] И.А. Кировская, Ю.А. Мурашко, Омск. науч. вестн., № 1, 66 (2004).

[6] И.А. Кировская, М.В. Васина, А.В. Юрьева, М.Е. Шалаева, Е.Н. Еремин, Ю.И. Матяш, С.А. Корнеев, Омск. науч. вестн., № 1, 32 (2014).

[7] В.М. Орловский, В.А. Панарин, Письма в ЖТФ, 43 (23), 11 (2017). DOI: 10.21883/PJTF.2017.23.45270.16824

[8] В.М. Орловский, В.А. Панарин, Оптика атмосферы и океана, 31 (3), 240 (2018). DOI: 10.15372/AOO20180316

[9] R.N. Gayen, K. Sarkar, S. Hussain, R. Bhar, A.K. Pal, Ind. J. Pure Appl. Phys., 49, 470 (2011).

[10] W. Mahmood, N.A. Shah, S. Akram, U. Mehboob, U.S. Malik, M.U. Sharaf, Chalcogenide Lett., 11, 461 (2014).

[11] B. Ghosh, D. Ghosh, S. Hussain, R. Bhar, A.K. Pal, J. Alloys Compd., 541, 104110 (2012). DOI: $10.1016 /$ j.jallcom.2012.06.063

[12] А.И. Ефимова, В.Б. Зайцев, Вестн. МГУ. Сер. 3. Физика, астрономия, № 2, 84 (2018).

[13] S. Adachi, in: Optical constants of crystalline and amorphous semiconductors (Springer, Boston, MA, 1999).

[14] Q. Zhang, X. Liu, M.I.B. Utama, J. Zhang, M. de la Mata, J. Arbiol, Y. Lu, T.C. Sum, Q. Xiong, Nano Lett., 12, 6420 (2012). doi.org/10.1021/n13037867

[15] H. Venghaus, P.J. Dean, P.E. Simmonds, J.C. Pfister, Z. Phys. B, 30, 125 (1978).

[16] S. Nakashima, S. Yasuda, Phys. Status Solidi B, 96, 211 (1979). 